• 研究报告・

\title{
优势种植被分类系统的逻辑分析与示例方案化
}

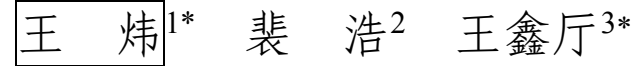 \\ 1 (内蒙古大学生命科学学院, 呼和浩特 010021) \\ 2 (内蒙古气象局, 呼和浩特 010010) \\ 3 (内蒙古工业大学能源与动力工程学院, 呼和浩特 010051)
}

\begin{abstract}
摘要: 逻辑学原理是各种分类系统科学性及规范性的必要检验工具。本文采用逻辑学原理检验基于优势种的《中 国植被》的植被分类系统, 结果发现目前常用的植被分类系统存在较多逻辑错误，需要予以纠正。于是，在强调植 物生活型分类系统和植被分类系统一致性的基础上，依据逻辑学原理给出建立植被分类系统的步骤和方法，提出 规范的植物生活型分类系统和植被分类系统示例方案。鉴于多建群种植被的客观存在及其存在形式多样, 在分类 系统中给出相应的位置——多建群种植被纲。同时, 针对国内植被分类学界从未形成统一的植被命名规则, 且又 有多种命名方式并存的现状，提出了函数命名法。
\end{abstract}

关键词：植被分类系统；生活型分类系统；逻辑分析；多建群种植被

\section{A logistic analysis on vegetation classification system based on dominant species with an illustrational scheme}

\author{
Wei Wang ${ }^{1 *}$, Hao $\mathrm{Pei}^{2}$, Xinting Wang ${ }^{3 *}$ \\ 1 College of Life Science, Inner Mongolia University, Hohhot 010021, China \\ 2 The Inner Mongolia Meteorological Bureau, Hohhot 010010, China \\ 3 School of Energy and Power Engineering, Inner Mongolia University of Technology, Hohhot 010051, China
}

\begin{abstract}
This paper aims to introduce a method to test vegetation classification systems based on the dominant species, in order to evaluate the accuracy of the classification system. If the test shows that there are errors in commonly used vegetation classification system, corrections are needed. To correct the existing classification system error, we must build a new system of classification. This paper presents a new vegetation classification system based on dominant species, and identifies the processes and methods to establish the classification system. Logic testing tools are the basis of examining the correctness of vegetation classification system. In this paper, we confirm that the principles of logic can be used for testing classification systems. Steps and methods to establish the vegetation classification systems are given and the new plant life-form and vegetation classification system are established. We suggest the concept of multi-constructive species vegetation, set, the classified status and present a clear vegetation nomenclature.
\end{abstract}

Key words: vegetation classification system; life-form classification system; logical analysis; multiconstructive species vegetation

事实上，植被分类的重要性早已远超我们的想 象，从20世纪中期植被分类学曾引发意识形态领域 的激烈冲突中可见一斑。从那时起，依特征种分类 的法瑞学派与以优势种作为分类依据的苏联学派 渐行渐远, 各自建立起独立的植被分类系统。这两
套系统互不相容，但却处理着相同的对象。植被分 类的重要性不仅在于它是人类认识复杂多样的群 落类型的需要，更在于植被分类系统汇集了人类对 植被的研究成果与认识水平。

中国学者受意识形态的影响, 尘封了刘慎谔、

收稿日期: 2015-05-06; 接受日期: 2016-01-06

* 通讯作者 Author for correspondence. E-mail: weiwang686@sina.com; wang_x t2002@163.com 
朱彦丞等在中国开展的依特征种进行植被分类的 工作(宋永昌, 2001), 紧随前苏联建立起依优势种分 类的植被分类系统。到1980年, 沉淀30余年的积累 汇集成长篇巨著—《中国植被》(中国植被编辑委 员会, 1983)。这部巨著凝聚了无数前辈学者的智慧 和艰辛岁月徒步科考的汗水, 对中国生态学界影响 巨大, 直至今日依然是中国植被分类学界的巅峰之 作。然而, 在这部著作中, 亦难免出现漏洞和错误, 这就需要后辈学者进行修订、补充和完善, 这是我 们的责任和义务。经过多年的研读与思考, 并结合 长期的遍及各地的考察, 发现贯穿《中国植被》始 终的植被分类系统是该书最需要完善的部分。本文 试图围绕这一问题展开论述, 期望引起广大同仁的 关注, 文中所表达的有些观点可能是片面的, 甚至 不尽合理, 谨希望广大读者根据需要从中汲取有价 值的部分, 为《中国植被》的完善尽一点微薄之力。

\section{1 《中国植被》所用植被分类系统中存在的 逻辑问题}

在此, 我们来分析这个植被分类系统。这个分 类系统中植被型组是其最高级分类单位, 也是对中 国或全球植被的第一级划分, 列举如下:

(一)针叶林植被型组

(二)阔叶林植被型组

(三)灌从和灌草从植被型组

(四)草原和稀树草原植被型组

(五)荒漠(包括肉质刺灌丛)植被型组

(六)冻原植被型组

(七)高山稀疏植被型组

(八)草甸植被型组

(九)沼泽和水生植被型组

植被型组(一)和(二)的划分依据是植物的叶型, 且只限于乔木群落。然而以具有退化叶物种建群的 乔木群落, 如木麻黄科植物, 却未能从这个系统中 找到位置。

如果把植被型组(一)和(二)看作乔木生活型为 建群种的代表, 则(三)代表灌木生活型建群的群落, (四)代表草本生活型为建群种的群落, 而植被型组 (五)的建群种有灌木和半灌木, 以及小(半)乔木, 那 么, 该植被型组中以灌木为建群种的群落同时也可 以归入到植被型组(三)中。同样, 植被型组(六)中以 灌木为建群种的植被同时可以被归入型组(三)中,
而以草本建群的群落似亦可纳入型组(四)中。

植被型组(七)的存在意味着高山上形成的灌木 群落如果不够密, 那就是高山稀疏植被, 如果足够 密, 那么它就是植被型组(三)。然而稀疏与稠密的密 度阈限是多少? 在建群种相同的情况下, 是否仅因 为群落密度不同就要分到不同的植被型中?

植被型组(八)和(四)中以羊草(Leymus chinensis)建群的群落: 一部分是用于区划草原的地带性植 被, 另一部分则在草甸植被(八)中占据重要位置。根 据《中国植被》的分类对群系的定义: “凡是建群种 或共建种相同的植物群落联合为群系”, 那么羊草建 群的群落当属于同一群系, 但是这个中级分类单位 却被植被型组这样的高级分类单位分隔开来了。

植被型组(九)中有以乔木建群的群落, 也有以 灌木、草本建群的群落。兴安落叶松(Larix gmelinii) 建群的植被可以在山地上形成高位沼泽, 也可以形 成被《中国湿地植被》(中国湿地植被编辑委员会, 1999)称之为兴安落叶松群系(Form. Larix gmelinii) 的森林沼泽, 当然更常见的是在山地上形成的“针 叶林”。同样的情况, 红砂(Reaumuria soongorica)作 为最耐旱的荒漠群落建群种, 在确定荒漠区时具有 重要意义, 同时这个物种还进入草原区, 深入到滨 湖带或低洼地形成红砂建群的灌从; 芦苇 (Phragmites australis)群落通常生长在沼泽中以近 乎纯群落的形态出现, 常被称为“挺水植被”, 但在 阿拉善荒漠区, 芦苇会在沙漠边缘形成大面积的草 甸群落, 与挺水植被相去甚远, 更有甚者, 在巴丹 吉林沙漠的一些沙丘上仍可见到芦苇的身影。可见 自然界中生态幅较广的植物种颇多, 沼泽生或水生 与陆生的界限并不严格, 因此, 依生境特点对植被 进行分类容易遇到上述类似的问题。

这里讨论的 9 个植被型组中前 4 个可以看作依 植物生活型进行的分类, 且植被型组 (一)和(二) 是 以叶型作为分类依据的, 即在一个等级中完成了两 个等级的划分; 后面5个当属依生境进行的植被分 类。这些依植被所处生境划分的子集还可以进一步 划分出依热量条件区分的冻原, 依水资源状况划分 的森林、草原、荒漠、草甸和沼泽, 又因海拔高度 独立出高山类型, 显然在这个等级中用于分类的标 准太多了。在一个等级上采取多标准进行划分, 势 必导致如前述羊草群系、红砂群落、芦苇群系、兴 安落叶松群系的情况。至于如此划分是否正确, 划 
分过程中是否可以使用多个标准, 以及如果这样划 分有问题, 那么问题出在哪儿等, 已经不是植被分 类学或生态学所能判定的问题了。这需要一门更具 概括性和指导性的学问来分析和解决。而诞生于古 老的亚里士多德时代的逻辑学恰恰是解决这类问 题的有效工具。

尽管与生物有关的所有学科, 甚至除数理逻辑 外的所有自然科学学科, 均对逻辑工具有强烈的需 求, 但相关学者却不是非常关心逻辑学的实际应 用。虽然, 我们不学语法也可以有效完成语言表达。 但就像判断复杂语言表达时需要语法依据一样, 面 对极为错综复杂的问题, 失去逻辑工具就会失去有 效判断、推理的准绳。

那么, 逻辑是什么? 欧文等说: “逻辑学是研究 用于区分正确推理与不正确推理的方法和原理的 学问” (张建军等, 2007)。张晓芒(2010)认为逻辑学 是一个包括有传统逻辑与现代逻辑各分支在内的
宏大的学科体系, 传统逻辑意义上的普通逻辑是 “一门研究推理或论证有效性的工具性的思维科 学”。较为激进的观点认为: “逻辑科学始终在事实 上研究的是客观世界的客观的逻辑结构和逻辑规 律” (龚启荣等, 2009)。较传统的观点认为逻辑是“研 究思维形式的结构及其规律和简单逻辑方法的科 学” (蔡贤培, 2000)。归纳起来, 逻辑学致力于研究 推理这种重要的、会引发创造能力的人类思想活 动。推理的工具是“三段论”，构成三段论的基础是 概念或词项。概念是逻辑学的基础。概念的划分是 揭示概念外延的一种逻辑活动(龚启荣等，2009); 是把概念(词项)外延(Box 1)分为若干小类以明确概 念(词项)外延的逻辑方法。被划分的指称大类的概 念(词项)称为母项，划分所得的指称小类的若干概 念(词项)称为子项; 把母项划分为子项是依据某个 属性进行的, 这个属性称为划分的根据或标准(何 向东, 2010)。

\footnotetext{
Box 1 外延和词项的含义

1. 概念或词项的外延: 就是词项指称的对象，词项指称的一类对象构成一个集合，这个集合中每一个元素都属于这个词项的外延 (何向东, 2010)。

2. 词项: 有学者认为, 词项是思维及其语言表达中一种具有确定意义的基本单位, 它的基本功能是能够充当简单命题成分中的逻 辑，因此自然语言中的实词以及实词性质的词组都是词项。概念则是反映思维对象特有属性的思维形态，事物所具有的性质、关 系、功能等等都是它的属性，其中有些属性是一类事物具有而其他类事物不具有的，这些属性就是特有属性。这说明词项和概念 具有不同的含义。亦有学者将概念作为思维结构的最小单位进行研究，在此意义上 “概念”与 “词项” 相同，本文选用后者。
}

借用逻辑学工具我们可以确定：植被分类同所 有的分类一样，也是一个概念划分问题，是将植被 这个大类的外延划分成多个小类的逻辑方法或称 逻辑活动; 同样，植被分类所划分的是概念，划分 的结果也是概念——无论我们如何划分, 地球上的 植被还依然如故地生活在那里, 并不会因我们的划 分而变化。

那么, 逻辑学拟定了哪些划分规则? 概念的划 分规则有 3 条:

(1)分类的唯一标准原则, 即每次划分必须按照 同一分类标准进行。每次划分 (从一个大类划分出若 干小类, 从上一分类等级到当前分类等级为一次划 分)的全过程必须遵循同一个划分根据，不能时而 用这个划分根据，时而又用那个划分根据，否则就 会产生“混淆根据”的逻辑错误。《中国植被》植被型 组级的划分就采用了多个分类标准或依据(如前
所述)。

(2)分类的彻底性，即划分出的子集的并集必须 等于被划分的母集。划分的各子项外延之和必须等 于母项的外延。根据这个规则, 划分不能多出子项, 也不能遗漏子项，否则，就会产生“多出子项”或“划 分不全”的逻辑错误。如前所述的退化叶乔木建群 的群落在分类系统中无归属的现象就属于划分不 全; 荒漠与灌从等植被型间的相容关系又会导致划 分中多出子项——除非人为强制。

(3)子项间的不相容关系, 即划分出的子集之间 必须是全异关系。划分出的任意两个子集的交集必 须等于空集，这反映了分类的清晰性。划分的子项 必须是相互排斥的，否则就会出现“子项相容”的逻 辑错误。例如，雨林植被型被划分为: 湿润雨林植 被亚型、季节雨林植被亚型、山地雨林植被亚型。 其中湿润雨林可被看作无季节变化的雨林, 季节雨 
林则是有干湿季节变化的雨林, 那么山地雨林地处 赤道无季节变化的生境时则当属湿润雨林, 地处具 干湿季节交替的热带生境时, 则为季节雨林。为此, 山地雨林植被亚型的出现导致这三个亚型“子项 相容”。

在划分中犯一个逻辑错误可能无意中就会引 发多个错误。至此可以发现: 上述有关划分的全部 逻辑错误在《中国植被》的植被分类系统应该都有 涉及。

如果一个分类系统出现上述逻辑问题, 补救的 方法只有一个, 就是主观地归类。例如欲将一个灌 丛多个群落归入上述《中国植被》的植被型组中, 是 灌丛和灌草丛植被型组, 或荒漠(包括肉质刺灌丛) 植被型组, 抑或是高山稀疏植被型组, 则完全依据 人为判定了。由此，《中国植被》的目的—“ “咉 各植被类型的固有特征及其与生境之间的固有联 系，而非人为分类”一受此分类系统所累，事实 上已趋于成为人为分类系统。将复杂的植被放进一 个逻辑混乱的分类系统中, 不采取人为强制的办法 是无法划分的, 因此出现了迫不得已而为之的人为 主观划分。

类似的问题在整个植被分类系统的各个等级 中都可见到。例如阔叶林植被型组被分为:

VI. 落叶阔叶林植被型

VII. 常绿、落叶阔叶混交林植被型

VIII. 常绿阔叶林植被型

IX. 硬叶常绿阔叶林植被型

X. 季雨林植被型

XI. 雨林植被型

XII. 珊瑚岛常绿林植被型

XIII. 红树林植被型

XIV.竹林植被型

其中前 4 个植被型按是否落叶来划分, 季雨林和雨 林则按热量带划分, 至珊瑚岛和红树林则属按生境 划分，竹林则依植物分类群划分。

其中的季雨林进一步划分为:

a. 落叶季雨林植被亚型

b. 半常绿季雨林植被亚型

c. 石灰岩季雨林植被亚型

其中的落叶季雨林群落与落叶阔叶林在归属上并 未被严格界定, 半常绿的概念难以把握。而珊瑚岛 多形成于热带、亚热带海洋中, 其上形成的植被与
常绿榈叶林、硬叶常绿阔叶林、季雨林、雨林, 甚 至红树林都有可能相似, 组成珊瑚岛的石灰岩与石 灰岩季雨林的基质极为相似。可以看出, 在极为重 要的基本分类单位植被型这个层次, 由分类标准非 唯一的逻辑错误导致群落归属势必由人为规定。此 外，混交林概念的使用则必须在空间分布相邻的植 被型间都设置混交植被类型，如常绿阔叶林、季雨 林混交林等, 尤其在混有竹林的群落中亦当设置常 绿阔叶、竹林混交林, 如此种种。上面列出的季雨 林 3 个植被亚型引发的混乱可能还会远超想象，因 为石灰岩季雨林中的建群种有落叶乔木, 也有半常 绿乔木, 因此在确定一个群落的分类位置时不免让 人为难。

《中国植被》在分类原则中强调: “本书采用的 是植物群落学原则, 或植物群落学-生态学原则, 即主要以植物群落本身特征作为分类的依据, 但又 十分注意群落的生态关系, 力求利用所有能够利用 的全部特征”。那么这个原则可以理解为在一次分 类中既要出现依据植被特征进行的分类, 又要出现 依生境进行的分类。因此, 宋永昌(2011)强调, “高级 分类单位偏重于生态外貌, 而中、低级单位着重种 类组成和群落结构”, 实际上就是为了避免产生上 述理解。

\section{2 植被分类的划分依据}

\section{1 植被分类划分依据的选择}

划分依据或称划分根据源于划分目的。反过来, 划分的目的也制约着划分依据，即限定划分所能选 用的依据。基于划分目的，用作划分依据的属性必 须是被划分母集的属性，而非外在的关联属性; 亦 即用于植被分类的性状必须是植被的特征, 而非生 境、分布等外在因素，因为用生境作为划分依据的 分类是生境分类，在此仅讨论植被分类。

植被的特征包括群落组成、群落结构以及群落 外貌三大部分。常常分别具体化为优势种、建群种、 常见种、偶见种, 生活型, 层片, 叶型、叶态, 季 相等。

与植被相关联的属性可以概括为生境, 包括植 被群落所处环境的水、热状况, 基质条件, 资源水 平，空间分布等诸多方面。而涉及生境类型划分的 工作早已为相邻学科所完成, 例如气候分类系统 中, 柯本(Köppen) (1953)依水热组合上的差异将地 
球上的气候划分为 24 个类型(周淑贞，1984)。此外, 为数众多的土壤分类系统也将植被着生的基质依 不同的目的划分为不同类型。因此植被分类系统没 必要强调相邻学科的成就, 至少, 植被分类不应作 为气候分类或自然地理分类下的延伸。换言之, 如 果各种生境分类系统能够代替植被分类而起作用, 那么植被分类就失去了存在的意义和价值。

《中国植被》中出现“混淆根据”逻辑错误较少 的部分, 也存在划分不彻底的问题。如针叶林植被 型组, 可进一步划分为:

I. 寒温性针叶林植被型

II. 温性针叶林植被型

III. 温性针阔叶混交林植被型

IV. 暖性针叶林植被型

V. 热性针叶林植被型

显然, 这一级的划分依据是生境中的热量条 件, 体现了热量带的纬向变化。然而, 由于跨热量 带分布的广生态幅建群种的存在, 使植被的划分出 现困难。例如, 侧柏(Platycladus orientalis) 建群的群 落可在吉林、辽宁、内蒙古(南部)、河北、山西、 山东、江苏、浙江、福建、安徽、江西、河南、陕 西、甘肃、四川、云南、贵州、湖北、湖南、广东 (北部)、广西(北部)见到, 其分布的热量带大致为从 中温带到亚热带, 至少对应于温性针叶林植被型和 暖性针叶林植被型。类似的植被, 如马尾松(Pinus maasoniana) 群落、华山松 $(P$. armandi) 群落均具有跨 热量带分布的特点, 前者从河南、陕西分布到云南、 贵州; 后者从山西、河南分布到云南、贵州。如果 将这些跨热量带的植被分别列入不同的以热量带 为依据划分的植被型中, 则又会出现高级分类单位 拆分低级分类单位的“多出子项”现象; 否则, 只能 将其强制在某一热量带中而忽视其在其他热量带 中的存在, 即所谓的“划分不全”现象。无论哪种情 况, 都不是正常分类系统应该出现的。究其原因, 实为以生境作为划分依据所致。

\section{2 植被分类与植被分区的区别}

植被分类的目的只有一个, 就是产生不同等级 的植物群落，而不论其分布在何处。

植被分区是植被地理分区的简称，是依植被的 特征及其空间分布特征而将地球表面或特定区域 的植被分为不同等级地理单元的过程。其目的是将 以植被为划分依据的特定空间划分成具有归属关
系的更小空间。我们常用到的术语“北方针叶林区”、 “夏绿阔叶林区”、“常绿阔叶林区”、“常绿硬叶林 区”、“季雨林区”、“热带雨林区”、“草原区”、“荒 漠区”、“稀树草原区”等等, 都反映着植被分区的成 果。由于这些术语中的“区”字在应用中常常被省略， 容易与植被分类相混淆。

由于常见的植被分区是以地带性植被为依据 划分的，故用作分区的一组植被常被称为该分区植 被, 如用于划分典型草原带的地带性植被统称为典 型草原植被; 用于划分夏绿阔叶林区的地带性植被 亦常称为夏绿阔叶林。前述的各个植被分区多有对 应的地带性植被。这些地带性或代表性植被通常具 有相近的生态适应能力, 占据着区域内的显域生 境, 反映该区域的环境特征。与地带性植被相对应 的，常常不作为分区依据使用的，生长于隐域生境 的“非地带性植被”亦常被概括为与其生境相对应的 植被，如草甸植被、沼泽植被。

无论地带性植被还是非地带性植被, 它们对其 生存的特定生境具有很好的适应能力。但由于植物 适应途径多样性客观存在, 具有相近适应能力的群 落不一定在分类归属上也相近，同样，同一物种建 群组成的群落亦不一定仅分布于单一生境中, 故 此，植被分类只能产生植被分类系统，不易同时产 生类似“草原”、“森林”之类的植被地理分区。当然, 如果在进行植被分类时产生植被分区成果而不导 致混乱当然更受欢迎。

\section{3 优势种植被分类系统示例方案}

依据上述逻辑学原则制定了内蒙古植被分类 系统。基于 《中国植被》的巨大影响，本次制定的 内蒙古植被分类系统将尽可能与 《中国植被》所采 用的植被分类系统、分类单位保持一致。

\section{1 分类等级、单位与划分依据}

参照《中国植被》的分类系统，本分类系统采 用其中的三级基本分类单位，分别是:

(1)植被型(Class)。为本分类系统的高级分类基 本单位, 依群落建群种的生活型划分, 即群落建群 种生活型相同的群落可以并只能归入同一植被型。 在此将植被型的英文定为Class而不是 Vegetation type是因为植被型这一级单位与Braun-Blanquet分 类系统的群落纲(Class)大体对应, 如此可使两个系 统有参照的可能性。 
(2)群系(Formation)。为植被型下的中级分类基 本单位, 依群落建群种划分, 定义为建群种相同的 群落唯一地属于同一群落。尽管包含的内容、等级 不同, “群系”及“Formation”术语几乎出现在所有的 植被分类系统中, 在《中国植被》分类系统中群系 与Braun-Blanquet分类系统的群团(Alliance)在等级 上很接近。

(3)群丛(Association)。为本分类系统的基本分 类单位, 划分依据是在层片结构相同的前提下, 各 层片优势种均相同的群落自然地归入同一群丛。这 个术语出现在很多植被分类系统中, 中英文名称都 很稳定, 且《中国植被》与Braun-Blanquet分类系统 在此等级上亦相当。

此外, 基于群落的建群种单一与否, 本分类系 统增加植被纲(Division)作为最高级植被分类单位。 由于过去提出的优势种植被分类系统未对多建群 种植被予以归类, 这就使得客观存在的多建群种植 被找不到自己的位置, 故而不得不设此分类单位。

\section{2 植物生活型}

本植被分类系统中的植被型依建群种的生活 型划分, 群丛划分所涉及的层片亦由生活型划分。 既然植物生活型是用于划分植被型的依据, 特定的 生活型必然对应于特定的植被型, 即生活型分类系 统必然与植被分类系统相呼应。因此植物生活型的 划分就成为植被分类中至关重要的基础工作。

\subsection{1 植物生活型划分原则和依据}

除前述关于划分的形式逻辑原则外，拟制订以 下生活型划分原则:

(1)非定量原则。为保证同种植物不会因定量指 标划分成不同层片, 不宜用定量的方法划分作为植 物外貌的形态特征。例如, 若将高度 $>25 \mathrm{~m}$ 的乔木定 为大乔木, 8-25 $\mathrm{m}$ 的乔木为中乔木, $<8 \mathrm{~m}$ 则为小乔 木, 这样的定量指标在实际应用中容易造成困难, 如会将同种幼树和成熟乔木处理为不同的层片。

(2)客观性原则。划分中尽量不选用渐变的特征, 以避免物种生活型判定中的人为性。

(3)去咒余原则。藤本植物、寄生植物、半寄生 植物、附生植物无论被划分为何类生活型, 在群落 层片分析中都属于层间植物, 这些植物亦不能成为 群落建群种, 故将这些物种列入生活型划分中的必 要性不强。如的确有必要确定这些植物的生活型归 属, 只要依其是否木本, 以及休眠芽和营养繁殖体
的位置来划分其归属即可。

(4)洁净原则。生活型系统的确定仅依据植物的 外貌特征，不与水生、湿生、中生等生态适应型相 混, 以避免生活型系统复杂化而导致的逻辑混乱。

在对植物生活型进行划分之前, 有必要对植物 生活型划分的原则和依据进行分析。常用术语植物 生活型有两个含义: 其一, 是植物进化出的所有外 貌特征的集合，是指植物生活型分类系统; 其二, 某一植物的生活型归属。由于不具亲缘关系的植物 可以通过趋同适应形成相同的生活型, 同一生境中 生长的植物也会进化出不同的外貌特征, 所以生活 型是植物不断进化的生存策略在外貌特征上的反 映。通常将在外貌上具有相同(似)特征的植物归为 同一类生活型。

\subsection{2 划分的植物生活型分类系统}

植物生活型系统设置如下:

I 木本植物——具形成层, 根和茎因增粗生长 形成大量次生木质部

\section{I-1 乔木一一具有明显主干的木本植物}

(1)针叶乔木——乔木裸子植物中的针叶 与鳞叶植物

(2) 阔叶乔木——乔木被子植物及乔木裸 子植物中的阔叶植物

(3)退化叶乔木——叶片退化成鳞片状或 膜质的乔木

\section{$\mathrm{I}-2$ 灌木一主干不明显的木本植物}

(1)灌木

II 半木本植物——落枝的木本植物

II-1 半乔木——落枝的乔木, 如梭梭属 (Haloxylon)植物

(1)半乔木

II-2 半灌木一一落枝的灌木

(1)半灌木

III 草本植物——具草本茎, 无形成层或形成 层活动时间很短, 不能形成大量的木质部

\section{A 固着生长植物}

A-1 多年生草本

III-1 草本地上芽植物——休眠芽或营养繁 殖体着生于地面之上的植物

(1) 草本地上芽植物, 如白车轴草 (Trifolium repens)植株匍甸

III-2 草本地面芽植物——休眠芽或营养繁 
殖体着生于土壤表面

(1)原地面芽植物一从植株基部生出具 有叶和花的地上枝

(2)半莲座状植物——植株下部为莲座状, 上部仍有具叶的地上枝

(3) 莲座状植物——植物体呈莲座状, 地上 无明显的茎

III-3 草本地下芽植物——休眠芽或营养繁 殖体位于土壤表面以下

(1)根茎型植物——休眠芽或营养繁殖体 位于根茎的植物，包括竹类

(2)块茎型植物——休眠芽或营养繁殖体 位于块茎的植物

(3)鳞茎型植物——休眠芽或营养繁殖体 位于鳞茎的植物

(4) 宿根型植物一一休眠芽或营养繁殖体 位于普通的根上

A-2 一、二年生草本

(1)一、二年生草本

$\mathrm{B}$ 漂浮生长植物

(1)漂浮生长植物

IV 肉质茎植物——植物具肉质茎, 叶通常退 化

IV-1 圆柱茎植物——肉质茎柱状

(1) 圆柱茎肉质植物

IV-2 叶状茎植物——茎枝扁平叶状

(1) 叶状茎肉质植物

$\mathrm{V}$ 叶状体植物

(1)苔藓植物

(2)地衣植物

(3)藻类植物

(4)真菌植物

该生活型分类系统未将竹类单独划分为独立 的生活型。理由是竹类植物休眠芽的位置和营养繁 殖体都位于根茎, 其根茎没有具次生生长的形成 层，根茎正常生长时不木质化，论及“本”，则其性 状与草本根茎植物相同; 而其地上部分“秆”属地上 枝，并非“本”，虽其在外表上可以表现为乔木状或 灌木状, 但可视为特化的地上枝, 又因竹类的秆不 具形成层, 无次生生长, 与其他木本植物有明显的 区别。如将竹类独立成生活型, 则将分别出现在乔 木或灌木生活型中，违背洁净原则。
由于桧柏(Sabina chinensis)、陆均松(Dacrydium pierrei)等二型叶裸子植物的存在, 导致针(刺状)叶 与鳞叶植物难以划分成不同的类型，故将鳞叶与针 叶乔木划为同一生活型，而将银杏等与阔叶无明显 区别的裸子植物归入阔叶乔木类。

植物的肉质茎亦为“本”之一种, 但与木本、草 本有明显区别，故肉质茎植物难以归入其他“本” 中。尽管肉质茎植物参与组成的群落在中国很少见 到，但出于“划分出的子集的并集必须等于被划分 的母集”原则，为避免“遗漏子项”，在此将此类植物 生活型独立出来。

\section{3 植被分类系统}

依上述植物生活型分类系统，将其中圆括号标 记的生活型类型作为定义植被型的生活型, 得出以 下植被分类系统:

一、单建群种植被纲

I 木本植物亚纲

I-1 森林植被型组
(1)针叶乔木植被型(针叶林)
(2)阔叶乔木植被型(阔叶林)
(3)退化叶乔木植被型

I-2 灌丛植被型组

(1)灌丛植被型

II 半木本植物亚纲

II-1 半乔木植被型组

(1)半乔木植被型

II-2 半灌木植被型组

(1)半灌木植被型

III 草本植物亚纲

A 固着生长植被次亚纲

A-1 多年生草本植被超组

III-1 地上芽草本植被型组

(1)草本地上芽植被型

III-2 地面芽草本植被型组

(1)原地面芽草本植被型

(2)半莲座状草本植被型

(3)莲座状草本植被型

III-3 草本地下芽植物植被型组

(1)根茎草本植被型

(2)块茎草本植被型

(3)鳞茎草本植被型

(4)宿根型草本植被型 
A-2 一、二年生草本植被超组

(1)一、二年生草本群聚

$\mathrm{B}$ 漂浮生长植被次亚纲

(1)漂浮植被型

IV 肉质茎植被亚纲

IV-1 圆柱茎植被型组

(1)圆柱茎植被型

IV-2 叶状茎植被型组

(1)叶状茎植被型

$\mathrm{V}$ 叶状体植被亚纲

(1)苔藓植被型

(2)地衣植被型

(3)藻类植被型

(4)真菌植被型

二、多建群种植被纲

VI 复合植被亚纲

(1)复合植被型

VII 多建群种植被亚纲

(1)共建种植被型

(2)多优种植被型

VIII 生长季内周期性变优势种植被亚纲

(1)生长季内周期性变建群种植被型

该分类系统所涉及的复合植被 (complex vegetation)仍采用前苏联学者Быков (1957)和Ярощенко (1966) 的概念, 即由于小地形有规律变化引起的不 同群落周期性更替的植被为群落复合体 (complex), 群落复合体中的各个组成群落的集合就是复合植 被。例如常见的“塔头”植被为顶部的湿草甸群落和 下部的浅水植被相复合的复合植被; 草原与荒漠交 错带上藏锦鸡儿(Caragana tibetica) 灌丛与短花针 茅(Stipa breviflora)相复合的复合植被等。

多优种植被出现在热带雨林和湿草甸中, 通常 是由于群落组成复杂, 物种多样性丰富而使建群种 的优势不明显, 以至于在短期内不容易确定其植被 类型。如果这些植被的建群种得以确定, 自然会在 单建群种植被纲中找到位置。当然也存在无法找出 建群种的群落。共建种植被是多优种植被的一种特 例, 是建群种明确的多优种群落, 通常是 2 个共建 种, 由 3 个以上共建种组成的群落罕见报道。共建群 落与多优种群落的区别在于前者的建群种是明确 的，后者则一定不明确。

生长季内周期性变建群种植被在湿地研究中
已被发现, 这样的群落也需要有一个名称和分类地 位, 而不能在一个生长季内将其分别称之为两个植 被类型，并给定两个分类位置。因此在此分类系统 中给这类群落设立了一个位置。

\section{4 群落命名}

3.4.1 存在的问题

《中国植被》没有显式地给出群落命名规则, 国内也一直缺少权威的植被命名法规，从而导致植 物群落的名称混乱。其错综性集中在对群从的命名 上，表现为:

(1)各层片优势种的排列顺序冲突。在现有的群 落命名方式中有学者将群落建群种放在群落层片 优势种序列之首，另一些学者则喜欢将建群种放在 序列的最后, 亦有学者注重木本植物的群落地位, 将其提到最前面，称之为“灌从化”及“疏林(化)”。例 如《中国植被》在其“植被分类的单位和系统”一节 中使用了两个群丛名称：“凸脉薹草-胡枝子-蒙古 栋林”和“羊草+大针茅十柴胡草原”。其中前一个群 从的建群种当是蒙古栎, 后一个群丛的建群种应是 羊草。这种处理会使人无法把握群落名称中最重要 的信息——建群种。此外, 《内蒙古植被》(中国科 学院内蒙古宁夏综合考察队, 1985)在命名中突出了 木本植物, 如在 |小叶锦鸡儿|-大针茅 + 䊁隐子草 + 溚草+冰草+硬质早熟禾群丛(Ass. |Caragana microphylla $\mid$ - Stipa grandis + Cleistogenes squarrosa + Koeleria cristata + Agropyron cristatum $+\mathrm{Poa}$ sphondylodes)中将非建群种的灌木小叶锦鸡儿提到 前面，以显示群落的灌从化特征。

(2)连接各层片优势种的符号混乱。目前国内用 于在群落名称中连接不同层片优势种名称的符号 有连字符或减号、逗号、加号、右单引号。这些符 号在不同学者的著作中表达为不同的意义：前述 “羊草十大针茅十柴胡草原”中的加号显然只是一个 连接符; 而“凸脉薹草-胡枝子-蒙古栋林”中的减号 与前面的加号相同，也同样是连接符，未增加或减 少对群落中优势种序列内容的表达。郑慧莹和李建 东(1993)在群落名称中采用减号连接，如“羊草-毛 秆野古草群丛”(Ass. Aneurolepidio - Arundinetum)。 周以良(1991)使用逗号表示群丛名称，如“越桔，杜 香，兴安落叶松林”表达为“Ass. Vaccinium vitsi-idaea, Ledum palustre, Larix gmelinii”。还有将 符号进一步细化的表达方式，如马尾松-桃金娘+岗 
松-芒萁群丛(Ass. Pinus massoniana - Rhodomyrtus tomentosa + Baeckia frutescens - Dicaranopteris dichotoma)中的加号用于连接同一层片中的多个优 势种, 减号连接的是不同层片的优势种。此外, 宋 永昌(2001)建议同一层片优势种间用减号或右单引 号连接。

(3)用多个层片优势种命名的不足。按照《中国 植被》给出的定义: “层片结构相同, 各层片的优势 种(南方某些类型中则为标志种)相同的植物群落联 合为群从”, 群丛的命名必须包含群落所有层片的 优势种。有学者鉴于植物社会学分类系统和植物命 名法规的简捷、有效和规范, 建议使用 “二名法”。 就前面列出的几个群丛名称而言, 郑慧莹和李建东 (1953)命名的“Ass. Aneurolepidio - Arundinetum”很 像二名法命名的群落。群落中的羊草和毛秆野古草 都是根茎型禾草, 无论按照哪个生活型分类系统, 这两个种都属于同一层片, 因此, 这两个种为群落 共建种。然而, 这样的二名法命名使群落中其他层 片的信息全部消失了, 此时的群从与群系间的等级 差也消失了。假使二名法能反映群落中两个层片的 优势种, 那么群从大约可以看作列出两个优势层片 优势种的亚群系——类似于植物分类学中的 “大种 派”, 属于“大群从派”。

前文出现过的“Ass. Vaccinium vitsi-idaea, Ledum palustre, Larix gmelinii” 中, 越桔和杜香都是灌 木, 属灌木层片。而“Ass. |Caragana microphylla| Stipa grandis + Cleistogenes squarrosa + Koeleria cristata + Agropyron cristatum + Poa Sphondylodes" 中除小叶锦鸡儿外均为地面芽丛生禾草, 只是按照 《中国植被》生活型可分为高丛生禾草和矮从生禾 草两个层片。然而, 每个层片有若干个优势种吗? 可以猜测, 过去的群落命名不是按照不同层片的优 势种序列进行的。

(4)非优势层片的优势种排列顺序未知。如果用 各层片优势种序列对群落命名, 那么这个序列如何 排列的问题目前尚未涉及到。

(5)使用拉丁文命名群落产生的牵强。由于植物 命名法规已被全世界有关学者接受, 群落名称中的 层片优势种名总要用拉丁文书写才属正规, 这就免 不了涉及到拉丁文的性与格及等级归属问题。 Braun-Blanquet分类系统用不同的后缀表达群落的 分类等级, 并按拉丁文法处理名称的性与格, 使群
落名称符合拉丁文的习惯。但是这样的做法不免有 些勉强。

\subsection{2 拟采用的群落命名规则}

通过分析群落命名中存在的问题可知, 无论如 何修补, 卷入上述命名规则混乱中都将使本次草拟 的植被名称混乱下去。因此, 采取新的命名规则是 无法回避的工作。在此, 拟采用“函数法”对群落命 名, 即将群落的分类等级作为“函数名”，优势种名 称为“变量”, 按照各个层片在群落中的数量由多到 少排序命名。如前面的凸脉薹草-胡枝子-蒙古栎林 表达为Ass (Quercus mongolica, Lespedeza bicolor, Carex lanceolata), 或Ass (蒙古栎, 胡枝子, 凸脉薹 草), 读为“有胡枝子, 凸脉薹草的蒙古栋群丛”。其 中优势层片的优势种, 即建群种蒙古栋居首位, 其 次为亚优势层片优势种, 即亚优势种胡枝子, 再次 为草本层片的优势种。如果某层有一个以上的优势 种, 则在列举它们时用逻辑运算符“ “ ” (和)连接。如 前面的Ass. Pinus massoniana - Rhodomyrtus tomentosa + Baeckea frutescens - Dicaranopteris dichotoma按照函数法命名当表示为“Ass (Pinus massoniana, Rhodomyrtus tomentosa \& Baeckea frutescens, Dicaranopteris dichotoma)”, 读为“有桃金 娘和岗松共层, 及芒萁的马尾松群从”。对于更高级 的分类单位, 同样采取函数法命名, 如Form (Leymus chinensis)或Form (羊草)表示羊草群系; 而 Form (Leymus chinensis \& Stipa grandis)或Form (羊 草 \&大针茅) 代表羊草和大针茅为共建种的群系, 读 为“羊草和大针茅共建群系”。至于Class (针叶乔木) 和Division (单建群种) 等高级分类单位大概多出现 在植被类型编目中。

严格意义上的共建群落在自然界并不多见。确 定共建群落的方法通常有两个, 其一, 在调查中测 得一个群落中出现两个数量很接近的建群种; 其 二, 长期监测测得不同年份群落建群种不同。对于 共建群落而言, 由于Ass ( $\mathrm{a} \& \mathrm{~b}, \ldots)=$ Ass ( $\mathrm{b} \&$ $\mathrm{a}, \ldots$ ), 在命名时建群种的顺序不影响群落性质。但 由于混用Ass $(a \& b, \ldots)$ 和Ass ( $b \& a, \ldots)$ 容易导致 编目时重复计数, 建议按建群种生活型系统的排列 顺序确定共建种的顺序。例如, 我们在内蒙古白音 锡勒牧场监测的实验样地为大针茅和羊草共建的 群落: 其中大针茅在前面的生活型系统中属原地面 芽植物, 列在根茎型植物羊草的前面, 故其命名当 
为: Ass (Stipa grandis \& Leymus chinensis, Artemisia commutata, Allium tenuissimum, Caragana microphylla), 读作“有变蒿、细叶葱、小叶锦鸡儿的大针 茅和羊草共建群丛”。至于各种混交林, 如果其群落 只有一个建群种, 按建群种归类型; 如果有两个或 两个以上建群种, 按共建种处理。

需要注意的是各层片优势种序列中出现的优 势种一定是层片的优势种, 不宜将群落中数量较多 的前几个种全部列进去。换言之, 群落中的每个层 片在群落名称中只出现一次, 而不论这个层片由多 少个种组成。前面的“Ass. |Caragana microphylla|Stipa grandis + Cleistogenes squarrosa + Koeleria cristata + Agropyron cristatum + Poa Sphondylodes" 按照函数法命名, 当称之为Ass (Stipa grandis, Caragana microphylla)。

如果某一层片中的优势种不易确定, 或组成这 一层片的物种种群空间分布强烈斑块化, 使群落不 同片段上该层片的优势种常有所不同，或者未充分 调查的野外记录，可以使用逻辑运算符“|”(或)将 该层片的各个物种连接起来。如前述的Ass. Vaccinium vitsi-idaea, Ledum palustre, Larix gmelinii群 落, 用函数法可以表达为Ass (Larix gmelinii, Vaccinium vitsi-idaea |Ledum palustre), 读为“有越桔或 杜香的兴安落叶松群从”。

对于复合群从，分别用函数法命名各个复合在 一起的群从, 中间用“ $\&$ ”连接, 如占据局部凸起生 境的藏锦鸡儿灌丛群落与分布于低处小生境的短 花针茅群落复合而成的复合群从, 该复合群落可表 达为Ass (Caragana tibetica) \& Ass (Stipa breviflora, Artemisia frigida, Lagochilus ilicifolius) 或Ass (藏锦 鸡儿) \& Ass (短花针茅, 冷蒿, 兔唇花), 读作“藏锦 鸡儿群丛与有冷蒿、兔唇花的短花针茅群丛复合的 群从”。

暂时或永久无法确定群落建群种的群丛, 记为 Ass (sp.1 | sp. $2|\mathrm{sp} .3| \ldots$ ), 即植物种名间用运算符 “|” (或)连接。其中的sp.1, sp.2...分别代表第 1 个种, 第2个种, ....... 且这个序列没有种群大小的排序。 如果可以分辨出不同层片, 这类群从可以描述为 Ass (sp.1 | sp.2 | ., sp.a | sp.b | .., sp.I | sp.II $\mid \ldots, \ldots)$ 。

周期性变建群种的群从不太常见, 因为不做详 尽的监测就无法查出这类群落的存在。在锡林河河
漫滩湿地上监测到在一个生长季内由水甜茅建群 到柳叶鬼针草建群的群落变化过程, 由于柳叶鬼针 草是一年生植物, 其变化不具有演替的性质。函数 法表示为Ass (Glyceria triflora $\rightarrow$ Bidens cernua, Agrostis gigantean)或Ass (水甜茅 $\rightarrow$ 柳叶鬼针草，小糠 草), 读作“有小糠草的水甜茅变柳叶鬼针草群从”。 其中“ $\rightarrow$ ” (箭头)指示生长季中建群种变化的方向。 通常一年生植物不能作为建群种标示群落的内在 规定性, 但这种仅在一个生长季内群落建群种就由 多年生植物变为一年生植物的情况与先锋群落或 群聚的情况不同, 故单独提出来。

综上, 我们可以避开混乱, 清晰地描述植被和 生态系统了。

\section{4 结语}

《中国植被》的植被分类系统面世已30余年, 这30余年被称为我国科学发展最迅速的时期, 但对 于《中国植被》中存在的逻辑错误却一直无人质疑, 无人修正。近年来出版的著作，如《中国植被图集》 (中国科学院中国植被图编辑委员会, 2001) 和《中 华人民共和国植被图》(中国科学院中国植被图编辑 委员会, 2007)仍沿用着《中国植被》的分类系统。 群落分类与群落名称是生态学各分支学科用以描 述研究对象的基础, 是生态学的通用语言, 关乎我 们所描述的研究对象是否准确, 我们依据文献引用 数据的那些群落是否具有可比性。因此, 基于优势种 的植被分类系统需要修正、补充、完善。当然, 植被 分类的系统不是唯一的，也可以编制出新的系统。

分类是科学研究的重要步骤, 是人类处理复杂 事物时首先用到的基本思想方法。目前, 需要进行 分类的事物越来越多, 建立起来的分类系统也相应 增多, 可能出现的逻辑错误也同样增加着, 因此迫 切需要一个检验分类系统是否正确的手段和方法。 比如，在《中华人民共和国国家标准：湿地分类 (GB/T 24708-2009)》中频繁出现分类标准多样化 ${ }^{1}$

(1) 例如, 在此标准中将沼泽湿地划分为苔藓沼泽、草本沼泽、灌从沼 泽、森林沼泽、内陆盐沼、季节性咸水沼泽、沼泽化草甸、地热湿地、 淡水泉/绿洲湿地, 共 9 个 3 级类型。其中前 4 个类型的分类依据是植被, 第 5 个类型是依基质中的盐分划分的; 第 6 个类型则涉及季节变化, 可 能是盐化草甸季节性积水而成, 抑或是浅水盐湖季节性干涸形成, 与内 陆盐沼, 湖泊类都有相重叠之处; 第 7 个类型则不属于沼泽，而是草甸; 至于地热湿地当不限于沼泽, 由于分类系统中地热湿地仅在此出现一 次, 热泉湖、热泉河亦当归入此湿地; 至于淡水泉属地下水出露现象, 想想泉城, 令其和绿洲湿地划为一类总觉勉强, 况且绿洲中草甸面积远 大于沼泽。在此沼泽分类系统中, 生长盐角草(Salicornia europaea)的内 
的情形, 也让人追问“湿地与森林、海洋并称全球三 大生态系统”的来源与分类依据 ${ }^{2}$ 。显然, 分类过程 中的随意性有可能使大量的研究工作缺乏可用性。 基于湿地国家标准进行的湿地调查, 其结果可能存 在混乱。有鉴于此, 建立起来的湿地分类系统也必 须通过检验，检验的工具需用到逻辑学。

基于优势种的植被分类系统的建立是一个循 序渐进的过程, 且需要保持植物生活型分类系统与 植被分类系统的相互呼应。《中国植被》建立起了 自己的植物生活型分类系统, 但又将其束之高阁, 着实有待完善。固然不能建立一个“高度> $25 \mathrm{~m}$ 乔木 植被型”或“8-25 m落叶阔叶林植被型”, 但把具有 退化叶的乔木物种排除在植被分类系统之外不合 情理。按照建立植被分类系统的步骤和方法, 本文 提出一个规范的植物生活型分类系统, 并由此产生 一个更加符合逻辑的植被分类系统, 以之为示例, 抛砖引玉, 希望引起同行的重视。

本文示例的植物生活型分类系统较为简化，还 可进一步划分。例如可将原地面芽植物分为从生禾 草和丛生杂类草, 再进一步分为高大的和低矮的等 等。然而, 植物生活型类型划分得越精细, 则群落 可划分出的层片就越多, 群从级群落分类单位划分 得就越细致，从而表现出“小群从”分类趋向; 反之 则为“大群丛”分类趋向。无论如何, 大群从最大到 群丛等于群系，小群从最小到趋于群落组成列表, 是为极限, 我们无法避免在此区间摇摆。

本文给出的植被分类系统为一基本框架，只划 分到植被型一级，有进一步划分的潜在空间。但在 群系等级上已可以将《中国植被》中没有被分隔的 群系都包容进来，当然，被分隔的群系整合后也可 融入这个系统中。调整命名方式后本文的植被分类 系统可以继承《中国植被》及过去全部优势种植被 分类的成果, 从这个意义上讲, 本文只是对过去植 被分类系统的规范化处理。

植被分类学界长期忽视多建群种植被的客观

陆盐沼当然可以归入草本沼泽中; 而绿洲边缘形成的盐爪爪(Kalidium foliatum) 群落即可归入灌丛沼泽, 又可归入绿洲湿地, 似乎也可在季节 性咸水沼泽中驻足稍息。这样的分类标准混淆错误使具体的湿地归属呈 “一女多嫁”态势。至于该标准中的类似问题不再赘述。

(2) 海洋和陆地生态系统因其面积相当和性质差异足够大而成为两个相 对应的生态系统集合, 部分湿地介于海陆之间, 因其属于水生生态系统 和陆生生态系统之间的居间生态系统, 另外部分与河流、湖泊等生境有 关。森林生态系统只是陆地生态系统的组分之一, 与其并列的生态系统 还有草原、荒漠、陆地湿地、草甸、冻原等。
存在。尽管前苏联学者早已认识到复合植被的群落 复合特征，但一直未能给出其在分类系统中的位 置。本文将复合群落、共建群落、多优势种群落和 变建群种群落归并到多建群种植被纲中, 扩大了原 来的优势种分类系统范围，为这些植被类型找到 归宿。

本文提出的植被命名法有效地规避了过去各 行其是的混乱命名，可以清楚地表达群落名称及群 落的层片组成关系, 突出了建群种。无论大群从分 类，还是小群丛分类，在命名的优势种序列中都会 表达出来，还可以直观地表达出多建群种群落的 特征。

\section{参考文献}

Cai XP (2000) Formal logic (Revised Edition). Central China Normal University Press, Wuhan. (in Chinese) [蔡贤培 (2000) 形式逻辑(修订本). 华中师范大学出版社, 武汉.]

Copi IM, Cohen C (translated by Zhang JJ, Pan TQ et al) (2007) Introduction to Logic, 11th edn. China Renmin University Press, Beijing. (in Chinese) [张建军, 潘天群等 (译) (2007) 逻辑学导论(第11版). 中国人民大学出版社, 北京.]

Gong QR, Zhu L, Wu CH Ye S (2009) An Introduction to Contemporary Formal Logic. Publishing House of Electronics Industry, Beijing. (in Chinese) [龚启荣, 朱霖, 吴春红, 叶森 (2009) 当代形式逻辑引论. 电子工业出版社, 北 京.]

He XD (2010) A Course of Logic. Higher Education Press, Beijing. (in Chinese) [何向东 (2010) 逻辑学教程. 高等教 育出版社, 北京.]

Inner Mongolia-Ningxia Complex Expert Team of the Chinese Academy of Sciences (1985) Vegetation of Inner Mongolia. Science Press, Beijing. (in Chinese) [中国科学院内蒙古宁 夏综合考察队 (1985) 内蒙古植被. 科学出版社, 北京.]

Song YC (2011) Recognition and proposal on the vegetation classification system of China. Chinese Journal of Plant Ecology, 35, 882-892. (in Chinese with English abstract) [宋永昌 (2011) 对中国植被分类系统的认知和建议. 植 物生态学报, 35, 882-892.]

Song YC (2001) Ecology of Vegetation. East China Normal University Press, Shanghai. (in Chinese) [宋永昌 (2001) 植被生态学. 华东师范大学出版社, 上海.]

The Editorial Committee of Vegetation of China (1983) Vegetation of China. Science Press, Beijing. (in Chinese) [中国 植被编辑委员会 (1983) 中国植被. 科学出版社, 北京.]

The Editorial Committee of Wetland Vegetation of China (1999). Wetland Vegetation of China. Science Press, Beijing. (in Chinese) [中国湿地植被编辑委员会 (1999) 中国 湿地植被. 科学出版社, 北京.] 
The Editorial Committee of Chinese Vegetation Atlas of the Chinese Academy of Sciences (2001) Vegetation Atlas of China. Science Press, Beijing. (in Chinese) [中国科学院中 国植被图编辑委员会 (2001) 中国植被图集. 科学出版 社, 北京.]

The Editorial Committee of Chinese Vegetation Atlas of the Chinese Academy of Sciences (2007) Vegetation Atlas of the People's Republic of China. Geological Publishing House, Beijing. (in Chinese) [中国科学院中国植被图编辑 委员会 (2007) 中华人民共和国植被图. 地质出版社, 北 京.]

Zhang XM (2010) Logic Is the Axe: Daily Reasoning Tool. Enterprise Management Publishing House, Beijing. (in Chinese) [张晓芒 (2010) 逻辑是把斧子: 日常说理的工具. 企业管理出版社, 北京.]

Zheng HY, Li JD (1993) Protection and Utilization of Grassland Vegetation in the Songnen Plain. Science Press, Bei- jing. (in Chinese) [郑慧莹, 李建东 (1993) 松嫩平原的草 地植被及其保护利用. 科学出版社, 北京.]

Zhou SZ (1984) Meteorology and Climatology. Higher Education Press, Beijing. (in Chinese) [周淑贞 (1984) 气象学与 气候学. 高等教育出版社, 北京.]

Zhou YL (1991) Vegetation of Daxinganling in China. Science Press, Beijing. (in Chinese) [周以良 (1991) 中国大兴安岭 植被. 科学出版社, 北京.]

Быков БА (translated by Fu ZZ) (1957) Geobotany. Science Press, Beijing. (in Chinese) [傅子祯 (译) (1957) 地植物学. 科学出版社, 北京.]

Ярощенко ПД (translated by Fu ZZ) (1966) Geobotany. Science Press, Beijing. (in Chinese) [傅子祯 (译) (1966) 地植 物学. 科学出版社, 北京.]

(责任编辑：黄祥忠) 